\title{
TODAS LAS MANSIONES DE \\ LA POESÍA. EL VEINTISIETE \\ EN LA CRÍTICA LITERARIA \\ DE ÁNGEL GONZÁLEZ ${ }^{1}$
}

\author{
Miguel Ángel García
}

Universidad de Granada

\section{LA GRAN TRADICIÓN}

Me gustaría comenzar recordando una afirmación radical y certera de Ángel González. No solo del muy estimable crítico literario, sino a la vez del extraordinario poeta que hubo en él, puesto que una y otra figura, crítico y poeta, son como es obvio indisociables (Payeras Grau, 2009: 145). En el segundo de los trabajos que dedica al Veintisiete, que ahora considera una "generación» y no un «grupo» como en el primero de ellos, introduce un apartado final donde estudia su presencia en las promociones poéticas posteriores. Nos dice allí que la poesía del Veintisiete ha llegado hasta la actualidad, hasta la última generación por entonces de poetas españoles, la de los ochenta, viva y ejemplar en distintos grados y diferentes registros, aunque siempre actuante en la obra de todas las promociones que la sucedieron a lo largo de más de medio siglo. Pone como ejemplo destacado de esa presencia entre los más jóvenes la dedicación crítica de su amigo Luis García Montero a la poesía de Alberti, y descubre en su «Égloga de los dos rascacielos» una continuación de la lectura vanguardista de la tradición, sobre todo la del Siglo de Oro, que llevó a cabo el Veintisiete (Díez de Revenga, 2003). La afirmación atinada y rotunda que me interesa subrayar 
viene después. La razón de tan insólita vigencia del Veintisiete le parece clara: si, como escribió otro poeta desdoblado en crítico, Luis Cernuda (Pozuelo Yvancos, 2003), «en la morada de la poesía hay muchas mansiones» (Cernuda, 1959: 712), los autores del Veintisiete, señala Ángel González (1993: 246), ocuparon todas las que estaban disponibles entre 1925 y 1935, «decenio verdaderamente fundacional de lo que fue, en sus líneas maestras, la poesía española del resto del siglo». Todas las mansiones posibles de la poesía, las vanguardistas y las tradicionales, las puras y las impuras, fueron ya habitadas por el Veintisiete en esa década prodigiosa, más decisiva quizás que la que abarca desde 1920 a 1930 (García de la Concha, 1991). Esa década fundacional no es sino el tiempo que también alcanzó a vivir Gabriel Celaya, uno de los maestros de Ángel González: el tiempo de «la revolución en la literatura» y de «la literatura al servicio de la revolución» (González, 1977: 292). Merece la pena destacar la lucidez de Ángel González al reconocer la gran tradición del Veintisiete, de la que las «generaciones» posteriores en efecto no pudieron escapar, aunque fuera para negarla; y merece la pena igualmente llamar la atención sobre su lucidez a la hora de sostener que todos los caminos de la poesía española del resto del siglo XX ya estaban de algún modo descritos, abiertos y hasta transitados por el Veintisiete.

Hasta cierto punto podría decirse, así pues, que la generación o el grupo del Veintisiete fue la auténtica morada de la poesía para todas las promociones de posguerra, que se dedicaron a habitar, cada una a su modo, las mansiones ya ocupadas durante aquel momento irrepetible. Naturalmente, Ángel González habla por propia experiencia. En conversación con Luis García Montero, confiesa que la famosa antología de Diego (Morelli, 1997 y 2007; Soria Olmedo, 1991; Teruel, 2007) fue muy importante para él y para muchos poetas de su generación. Incluso, podría añadirse, para los poetas de la primera promoción de posguerra, como algunos de ellos han reconocido más de una vez. Pese a que era un libro dificil de encontrar, "todos o casi todos dimos con él en el momento oportuno» (en García Montero, 2002: 16). En esta antología pudieron conocer, continúa diciendo, la obra de los poetas delVeintisiete, retirada, con pocas salvedades, de las librerías. Más importante es lo que añade a continuación: «Su lectura nos permitió incorporarnos a la tradición moderna de la gran poesía española del primer tercio del siglo XX» (ibíd.). Modernidad: esto es lo que significaba el Veintisiete para los aprendices de poeta en el áspero mundo del primer franquismo. No exagera Ángel González, por lo tanto, 
cuando define el hallazgo de esa antología como providencial: «Sin su lectura, mi repertorio de influencias o de modelos, imprescindible para quien comienza a escribir poesía, hubiera sido mucho más pobre y anacrónico» (ibíd.). No era la primera vez que el poeta, y no tanto el crítico, se expresaba en estos términos. Hablando del exilio interior, puntualiza que dentro de España no era posible encontrar los modelos literarios que los jóvenes poetas necesitaban, prescindiendo de algunos ejemplos que habían salido «de nuestras propias filas». Para los poetas, «tan dependientes de la tradición de su propia lengua», resultaba particularmente grave la necesidad de encontrar apoyaturas en el pasado: «Para no quedarnos en el anacronismo, los poetas de mi generación - la más desamparada y desconcertada entre todas las de la posguerra- necesitábamos tomar contacto con una tradición más amplia» (González, 1991: 262). Por supuesto, esa tradición que podía salvar (nuevamente) del anacronismo poético o cultural era la republicana, la que estaba en «la zona proscrita del exilio». Hablar del exilio republicano, afirma poco después, «es otra manera de seguir hablando de la generación del 27» (González, 1993: 236). Esto es, de la tradición universalizadora o europeizadora de España, en la que juega un papel decisivo el Veintisiete (Soria Olmedo, 1988, 2007 y 2010; García, 2001a y 2011). No en balde, Ángel González describe así cómo la toma del poder por el general Franco tuvo efectos desoladores sobre la cultura española:

Durante el primer tercio del siglo XX España había logrado realizar al fin una vieja aspiración que se remontaba a los albores del siglo XVIII, integrarse en la cultura europea. $\mathrm{Y}$ esa integración se produjo de modo brillantísimo: baste recordar los nombres de Picasso, de Falla, de Buñuel, de Juan Ramón Jiménez (todos ellos exiliados, por cierto), y de otros poetas integrados en la llamada generación del 27 para advertir que, en muchos aspectos, España, la España anterior a la guerra civil, ocupaba posiciones de vanguardia o privilegio respecto a Europa (González, 1991: 254-255). 
Aparte de esta tradición amplia, la generación de Ángel González contaba para sus designios literarios con el ejemplo de algunos primeros poetas de posguerra como Celaya, Nora, Hierro o Blas de Otero, por mucho que a la vez discrepara de ellos sobre cómo entender la poesía social; pero elVeintisiete seguía quedando como un ejemplo casi inaccesible, precisamente por la fractura que la guerra trajo en el campo de la producción y la distribución cultural: "Completar el mapa de la generación del 27, de la que yo tuve noticia fragmentaria y muy insuficiente por la antología Poesía española contemporánea preparada por Gerardo Diego, fue una tarea trabajosa y larga que acompañó e iluminó nuestros primeros pasos en la escritura» (González, 1991: 263). Han de introducirse ciertos matices, sin embargo, en ese acompañamiento e iluminación que supuso el Veintisiete para los jóvenes interesados en el realismo crítico; porque, advierte Ángel González, durante los penosos años de posguerra no se trataba tanto de reanudar los vínculos con una "tradición rota», aunque por supuesto así fuera, como de crear una cultura disidente con respecto a la cultura oficial. Desde este ángulo de visión, libros de poemas como Alegría, de Hierro, y Tranquilamente hablando, de Celaya, ambos de 1947, le parecen las primeras muestras de una literatura inconformista, y desde luego de mayor trascendencia que otros más aireados en su día, como Hijos de la ira (1944), de Dámaso Alonso. Pese a que González no duda en afirmar que Alonso estaba, cuando escribió ese libro, dentro del sistema del Régimen y que nunca dejó de estarlo, y pese a ver en él un poemario básicamente religioso donde su autor clamaba por la miseria del mundo, termina reconociendo su valor a esta actitud poética «frente a la versión heroica que ofrecían con unanimidad los integrantes de Juventud Creadora y demás poetas garcilasistas» (ibíd.: 258). Todo esto, concluye, preparó el camino para la literatura crítica de los años cincuenta.

Nuestra historiografia literaria suele señalar el papel relevante de otro libro publicado, como el de Dámaso Alonso, en 1944: Sombra del paraíso, de Vicente Aleixandre, que también habría ayudado a romper con la cristalización paralizadora de la poesía española por entonces. Sin hacer explícito ese título, Ángel González, al desarrollar la mencionada falta de modelos literarios para los jóvenes poetas, se apresura a aclarar que Aleixandre representó el «papel de padre y consejero de casi todos», pero que "para muy pocos 
fue modelo en un sentido estrictamente textual»; es el maestro del Veintisiete, curiosamente, quien a partir de Historia del corazón (1954) atempera su paso al de los poetas más jóvenes (González, 1991: 262). No anda equivocado si se repara en que la poesía de Aleixandre solo se aproxima a los tonos realistas o temporalizadores, aunque no críticos o sociales (García, 2001b: 555-557), con Historia del corazón, que inaugura su segunda etapa o "cosmovisión» en la terminología crítica de Bousoño (1977). No obstante, en otra ocasión sí que se refiere de modo explícito al poso de disidencia crítica que podía encerrar un libro anterior como Sombra del paraíso. Tratando de situar en su contexto al Celaya existencial y social, describe la poesía española de posguerra como un bloque unánime y monótono, como un gran rechazo de lo que la vida tiene de histórico y de actual en su conjunto. Quien emite este juicio es otra vez el crítico literario y el poeta históricamente muy concreto que casi siempre determina los razonamientos del primero. Los «diez mil poetas garcilasistas», argumenta, se apoyan para su retirada del campo de la realidad en la interiorización, el intimismo, la reducción de la circunstancia del personaje poético a su ámbito doméstico, la vuelta al pasado, el refugio en la intrahistoria o el tema de Dios. Mediante la religiosidad, dictada por la mala conciencia o incluso por la mala fe antes que por la fe a secas, se trataba de escamotear el tiempo presente, el alejamiento de la vida, ilusorio en cualquier caso. En este marco, Dámaso Alonso y Vicente Aleixandre son los primeros en romper "parcialmente», con sus dos libros excepcionales, ese monótono panorama:Alonso, clamando al cielo y dando cuenta de su horror ante el tiempo histórico inmediato, con una poesía que, sin dejar de ser religiosa, tiene entonces el «extraño valor de una revelación, de una denuncia»; Aleixandre, evadiéndose hacia un tiempo pasado, hacia la sombra de un paraíso perdido, «tal vez movido también por el deseo de evitar el inhabitable presente; pero en ese desplazamiento no se advierte mala conciencia ni la consiguiente religiosidad, sino una profunda pasión, igualmente insólita, por el hecho elemental de la existencia» (González, 1977: 295).

Pero este elementalismo del primer Aleixandre, que se cierra justamente en Sombra del paraíso, no podía servir de referente directo para quien, como Ángel González, iba a buscar una relación dialéctica de la poesía con la realidad. En Sin esperanza, con convencimiento (1961) incluye un soneto dedicado a Aleixandre, por su libro La destrucción o el amor (1935); un homenaje, con intertexto incluido (Rivera, 2006: 44), que el poema hace extensivo al primer 
gran estudioso de la poesía aleixandrina, Carlos Bousoño (Payeras Grau, 2009: 135-136). Puede suponerse aun así la insuficiencia del modelo elementalista aleixandrino, para el Ángel González social y el crítico derivado de él, a través de la persona (poética) interpuesta de Celaya. Pensemos en este planteamiento, que desarrolla en unas notas posteriores sobre intertextualidad e interdiscursividad en la poesía de Celaya: todavía como Rafael Múgica, se encuentra con el surrealismo, en concreto con La destrucción o el amor, y se limita en principio a reiterar la cosmovisión aleixandrina, en la que la pasión erótica equivale a un impulso elemental que conduce a la destrucción, a la disolución en la totalidad del cosmos; aquí intuye Múgica, afirma González, la pérdida del yo, la fusión con lo otro, con lo cual inicia un proceso radical que lo va a llevar a desembocar en Celaya, en el poeta social. Para llegar a este, con todo, Múgica tendrá que «romper por dentro la cosmovisión aleixandrina», sacando del esquema la pasión erótica, trasladando ese deseo de fusión «desde el reino de la Naturaleza a los dominios de la Historia: el espacio de "lo otro" en el que se disuelve la individualidad del poeta puede ser también el conjunto de "los otros”" (González, 1994: 330; García, 2012: 296). De modo que Celaya, y aquí se transparenta a la vez el Ángel González social, desarrolla las posibilidades éticas que no podían deducirse de la imagen de la «destrucción o el amor», y acaba historizando un deseo de fusión, de anulación de la individualidad o del yo, que en la cosmovisión aleixandrina se reducía a la Naturaleza.

\section{OTRAS LECTURAS Y HOMENAJES}

Ni el Alonso ni el Aleixandre de la primera posguerra podían ser más que modelos parciales para el poeta social que se delineaba detrás del joven Ángel González, quien sin embargo intentaba enlazar, en primer lugar como lector, con la tradición amplia, liberal, de la España republicana y exiliada y, más en concreto, con la morada de la poesía que había representado el Veintisiete. Él mismo ha contado cómo al final de su adolescencia, cuando cae enfermo de tuberculosis, comienza a insistir en la lectura de poesía, sobre todo en la del Veintisiete, y descubrió a Juan Ramón Jiménez, que constituyó para él un deslumbramiento. Tanto Juan Ramón como los poetas del Veintisiete fueron en aquella época su «máximo descubrimiento», aunque matiza que a Cernuda lo conoció después: «Cernuda no era entonces, en 1943 o 1944, tan admirado y valorado como 
otros de la generación; seguramente por eso tardé en leerlo. Mis primeras lecturas de la generación fueron Alberti, Lorca y Gerardo Diego» (González, 1990: 431). Son datos interesantes para pulsar la huella delVeintisiete en la poesía de Ángel González. Por lo que se refiere a Cernuda, desde luego no le otorga el papel de magisterio que le asignan otros compañeros del grupo del 50 como Valente, Brines y sobre todo Gil de Biedma, que como se sabe propone al Cernuda en contacto con la tradición poética anglosajona como ejemplo para librarse, precisamente, de la influencia determinante del Veintisiete (García, 2013a y 2013b). Ángel González parece ser muy consciente de ese papel fundamental de Cernuda - del 50, incluso desde Cántico en adelante (Talens, 1990; Siles, 2002; Jiménez Millán, 2002)— cuando señala, no sin su habitual ironía, que la influencia de este "caló hasta los huesos a no pocos poetas de los últimos años» (González, 1991:263). De todos modos, se ha venido señalando alguna presencia intertextual de Cernuda, como de Salinas (Rivera, 2006: 49-50; Díaz de Castro, 2006: 98; Payeras Grau, 2009: 128), en Otoños y otras luces (2001).

Al igual que Juan Ramón Jiménez, Góngora también fue un deslumbramiento, según propia confesión, para el joven lector de poesía que había comenzado por aprenderse cuando niño el $A z u l \ldots$ dariano de memoria. Sobre todo porque la lectura de Góngora «incidía en la reelaboración del Siglo de Oro que hicieron los del 27, poesía de corte clásico como algunos sonetos bellísimos de Alberti, o bien el tratamiento vanguardista de motivos barrocos — pienso en la Fábula de Equis y Zeda- que hizo Gerardo Diego, a quien leí con mucha atención cuando era joven» (González, 1990: 433). Tengamos en cuenta el aprecio que hace de la «Égloga de los dos rascacielos», aprecio que, como dijimos más arriba, tiene mucho que ver con el gusto por esa síntesis entre tradición áurea y novedad practicada por el Veintisiete. No es de desdeñar el detalle de que Ángel González confiese la lectura más bien del Diego creacionista, ya que el Diego de los «poemas humanos» le interesaba, pero le entusiasmaba fundamentalmente su poesía ultraísta o creacionista. Es un síntoma de que, para él, también la morada de la poesía tiene muchas mansiones, aunque a partir de Áspero mundo (1956) decidiese habitar una muy concreta e inconfundible. Puede afirmarse, con Rovira, que, aunque le resulten distantes en lo personal y estético, Ángel González busca sus modelos de rigor poético, de obra bien hecha, en los grandes poetas de antes de la guerra: «Igual que Ángel González, Gil de Biedma, Goytisolo, Barral o Brines, dificilmente se explicarían 
sin contar con la generación del 27» (Rovira, 2006: 60). Todavía cabría añadir algunos otros datos, estos otros más biográficos, en el mismo sentido. Por ejemplo, la entrevista que hace a Gerardo Diego para La Estafeta Literaria, en la época en que intenta ejercer el periodismo (González, 1990: 423; Jiménez Millán, 2006: 88); o bien el encuentro con Aleixandre, «maestro y consejero excepcional de jóvenes poetas», por mediación de Bousoño, que le anima a presentar Áspero mundo al Premio Adonais (González, 1990: 445). José Hierro llega a reconocer, a este respecto, la serie interminable de discusiones que tuvo con Aleixandre y Bousoño, que por entonces vieron en Ángel González «al futuro poeta que yo no supe ver» (Hierro, 1997: 58). Precisamente, a través de Aleixandre entra en contacto con el grupo de Barcelona. Tanto Barral como Gil de Biedma o Goytisolo han recordado, en diferentes ocasiones, cómo llegaron a confundirle, la primera vez que acudió a la tertulia de los Barral, con un policía o un informador, y cómo, ante la actitud de Ángel González, que bebió silenciosamente durante toda la noche, hubo que telefonear al día siguiente a Aleixandre para salir de dudas sobre la verdadera identidad de aquella especie de convidado de piedra (Gil de Biedma, 1985: 33; Goytisolo, 1998: 20). A Jorge Guillén, en suma, y por aquí volvemos a los detalles que guardan más relación con la biografia literaria, le dedica un poema de homenaje en Prosemas o menos (1985), unas glosas que de todos modos muestran la distancia de quien las escribe con la voluntad de orden y la percepción de una realidad perfecta e inmutable que caracterizan la primera poética guilleniana (Díaz de Castro, 2006: 103; Payeras Grau, 2009: 144).

\section{JUAN RAMÓN JIMÉNEZ, MACHADO Y EL VEINTISIETE}

Para terminar el capítulo de la lectura que, como poeta, Ángel González lleva a cabo del Veintisiete, hay que tener muy en cuenta, en fin, la siguiente confesión: «Tengo la seguridad de que la poesía de estos autores me influyó desde el principio. Y sobre todo, inevitablemente, Juan Ramón Jiménez» (González, 1990: 431). Se refiere al Juan Ramón de la Segunda antolojía poética (1922), que a su vez se convierte, como es bien sabido, en el maestro del primer Veintisiete, el de la poesía pura y deshumanizada, para entendernos. Ese Jiménez, reconoce Ángel González, le abrió un mundo nuevo. Incluso, llegó a ser para él el único poeta, hasta el punto 
de tapar al Machado que tan decisivo iba a ser después para su poética: «Más tarde rectifiqué esta opinión, y he pasado a considerar que Machado es el gran poeta de su tiempo" (ibíd.: 431). La admiración inicial de González por Juan Ramón Jiménez dejó en un segundo plano a Machado, como ocurrió entre los poetas del aludido primer Veintisiete, y en general en la poesía española hasta la llegada de la posguerra. No es casual, entonces, que Ángel González dedicase buena parte de sus esfuerzos de crítico literario, y de historiador de la literatura, a desentrañar la poesía de uno y otro maestro, sobre todo del segundo (Abad, 1990: 55-56; Payeras Grau, 2009: 140-141). El desplazamiento de una dedicación crítica (la de Juan Ramón) por otra (la de Machado) debe comprenderse a la luz de los supuestos fundamentales de la poética del autor. El propio Ángel González reconoce que su libro sobre Jiménez, de 1976, manifiesta su admiración por él, aunque ya con algunas reservas, las mismas que lo llevan a ironizar sobre su perfeccionismo en una «diatriba-homenaje» del citado Prosemas o menos (Payeras Grau, 2009: 141-142). Juan Ramón renovó, a su juicio, el lenguaje poético español, mientras que Machado, que fue probablemente "un poeta en el último extremo del romanticismo», sin novedades formales, no lo hizo. Pese a que le deslumbró en un principio lo que en Juan Ramón había de nuevo, «como les pasó a los poetas del 27, que aprendieron en él un nuevo lenguaje, una escritura nueva» (González, 1990: 431), luego Machado le acabó pareciendo un poeta mucho más hondo, rico, misterioso y profundo.

La aludida conversación con Luis García Montero también aporta, a este propósito, noticias muy interesantes. Nos habla aquí de cómo, desde los 18 a los 21 años, dedicaba diariamente varias horas a leer la Segunda antolojía, y de cómo a esa edad esta experiencia, tan prolongada y constante, acabó imprimiendo carácter. Hasta tal punto que, en sus primeros intentos de escritura, fue un aprendiz de poeta "marcada e ingenuamente juanramoniano» (en García Montero, 2002: 17). Lo mismo le pasó, añade, a la mayoría de los poetas delVeintisiete, aunque en ellos la influencia del maestro, bien matizada, no fue en absoluto mimética. De la Segunda antolojía lo que le atrajo fue la «combinación irresistible» de los logros más atractivos del Juan Ramón romántico-modernista, retocados o revividos con eficacia, y los poemas nuevos de su segunda etapa, la de la poesía desnuda. Indudablemente, fue en exclusiva el poeta desnudo el que sedujo a los poetas del Veintisiete en su momento puro o deshumanizado. A ese Jiménez de la poesía desnuda, coincidente con el que manifiesta en un aforismo que «quien escribe 
como se habla irá más lejos que quien escribe como se escribe», Ángel González lo sitúa, con indudable acierto, a la zaga del Bécquer que postula un lenguaje "desnudo de artificio». Es un rasgo juanramoniano que por fuerza había de valorar la poética de Ángel González, tan próxima a la lengua hablada y al Machado/ Mairena que traduce la ampulosa frase «los eventos consuetudinarios que acontecen en la rúa» por la más cotidiana «lo que pasa en la calle». No por casualidad indica en otro lugar que los que siguieron ese alegato de Bécquer por una poesía natural y desnuda de artificio se cuentan entre quienes escribieron los mejores versos en la España del siglo XX: Machado, el Juan Ramón de la poesía desnuda, Luis Cernuda o Gil de Biedma (González, 2002: 481-482). Y, por supuesto, él mismo. No obstante, advierte Ángel González, la poesía desnuda juanramoniana no siempre recuerda la palabra hablada, seguramente por la «extremada selección léxica que exigía su ambición de pureza lírica» (en García Montero, 2002: 17).

En realidad, el Juan Ramón desnudo muestra sus distancias con respecto a la pureza de los jóvenes del Veintisiete; de aquí que se desmarcase, sintomáticamente, del homenaje gongorino, en el que tal pureza alcanzó cotas de paroxismo (García, 2010). Ángel González concluye, y de nuevo van aquí de la mano el poeta y el crítico literario, que el magisterio de Jiménez en el acercamiento de la poesía al lenguaje cotidiano es dudoso: «Con el paso de los años, mi fervor inicial por Juan Ramón ha ido perdiendo grados» (en García Montero, 2002: 17). La conclusión sobre la poesía desnuda a la que llega en su análisis del famoso poema de Eternidades (1918), «Vino, primero, pura», viene a ser la misma: el intento de desnudar por completo la poesía, de hacer olvidar la forma, como dice Juan Ramón en las notas a la Segunda antolojía, está condenado al fracaso. La forma o los procedimientos por los que un texto es poesía y no otra cosa, afirma González, son al fin y al cabo imprescindibles. El mismo Jiménez habría sido consciente de ello, y por eso "se dedica a cambiar los trapitos inevitables por otros de color "carne de prosa" para darnos — con éxito, justo es decirlo- la impresión de total desnudez» (González, 2004: 180). No se podrá negar coherencia a los planteamientos críticos de Ángel González. Refiriéndose a la esencialidad lírica buscada por Machado, apunta que esta exige alguna clase de artificio: «Bécquer hablaba de una poesía sin artificio, pero esa poesía no existe. Bécquer debería haber hablado de una poesía "sin artificio demasiado visible", que es en la que seguramente estaba pensando» (González, 2002: 482). 
Más allá de la admiración y la influencia que el Juan Ramón Jiménez desnudo, o el Veintisiete vanguardista y puro que lo encumbró como maestro, pudieran haberle despertado en un inicio, Ángel González acabó derivando, por las exigencias internas de su propia poética, hacia el magisterio machadiano, hacia el poeta que le mostró

el camino de una palabra ética dispuesta a hacerse cargo de las impurezas de la historia, de una intimidad que se piensa en su constitución comunitaria y que se sabe atravesada por las causas civiles, de una expresión personal con voluntad de elevarse a categoría social, de un lenguaje poético forjado en el seno de los pactos comunicativos y empeñado en hacerse comprender — como quería Mairena— «por las mismas piedras de la calle» (Iravedra, 2008: 82).

A la poesía de Machado llega relativamente tarde, en cualquier caso, como él mismo reconoce. Esto es, una vez que se le pasó el deslumbramiento juvenil «por lo nuevo", un valor que asocia de forma implícita al Juan Ramón desnudo y al vanguardismo del Veintisiete. Machado, aclara, no tuvo la superstición de la novedad, lo que lo hizo parecer un poeta viejo en el contexto del arte de entreguerras: «Superada la fascinación un tanto infantil ante "lo nuevo", relecturas más atentas de Machado me permitieron descubrir, bajo su lenguaje poco o nada novedoso, un mundo complejo y hondo de ideas y de sentimientos que irradia un inagotable halo de sugerencias» (en García Montero, 2002: 18). La adhesión a la poética machadiana marca, pues, el punto de disensión con el arte puro en torno al cual se conforma el Veintisiete. En pleno auge de la poesía pura y las vanguardias, afirma González, Machado tuvo el acierto de elaborar su obra con lo que esos movimientos trataron de tirar por la borda: las preocupaciones éticas y políticas, la aproximación objetiva a la realidad, el tratamiento irónico y dialéctico de una serie de preocupaciones, o la armonización de las contradicciones entre sueño y realidad, intuición y razón, tiempo e historia, intimidad y otredad, prosaísmo y lirismo, lenguaje cotidiano y palabra esencial. La lectura de Machado, concluye, sigue siendo «un excelente antídoto contra las nuevas tendencias que insisten en alejar el arte de la vida» (ibíd.). No otra cosa hizo el Veintisiete, como es bien sabido, bajo la estética de la deshumanización y la pureza. 
A estos dos conceptos, deshumanización y pureza, ya dedica Ángel González un epígrafe en la introducción a su antología del "grupo poético de 1927». Habla aquí sobre todo el crítico, que trata de dibujar un panorama completo y más o menos escolar para el interesado en ese conjunto de autores, pero, como no podía ser de otro modo, se detecta entre líneas al poeta. Para empezar, ve en $L a$ deshumanización del arte (1925), más que un diagnóstico objetivo, la exégesis de un arte impopular, minoritario, incontaminado, alejado de toda realidad que no fuese la creada por una actitud exclusivamente estética. La mayor parte de los integrantes del grupo del Veintisiete no se mostró en modo alguno ajena, a su modo de ver, a los impulsos de aristocratismo y pureza que Ortega propugnaba. Lo que los aproxima con fuerza a las corrientes que Ortega calificó de deshumanizadas es «un afán impreciso de pureza» (González, 1976: 212). Es lo que Ángel González observa en el prólogo de Diego a su famosa antología de grupo, la de 1932, cuando alude a «una pureza de ideales muy alejados del campo raso, mezclado, turbio, de la poesía literaria corriente» (en Soria Olmedo, 1991: 668). Al mismo tiempo, se hace eco del Jorge Guillén que, ya lejos de esas corrientes, reconoce que él y sus compañeros fueron acusados en sus comienzos de fríos, abstractos, herméticos e intelectuales (Guillén, 1969a: 405-406). Importa subrayar, sin embargo, que González nunca pierde de vista la Historia de la poesía, y sobre todo la Historia, en sus análisis. Por eso agrega que, después de la guerra civil, «algo parecido a la mala conciencia» llevaría a muchos de esos poetas a negar lo que había constituido un ideal estético en su juventud, "cuando la palabra "pureza” no tenía la carga negativa que más tarde adquirió» (González, 1976: 213). Entre esos poetas que abjuraron de la pureza,Ángel González destaca a Jorge Guillén, "el más afecto a los ideales de un arte deshumanizado y puro», que sin embargo, ya como crítico, en el trabajo dedicado a su generación, trata de «limpiar del "pecado" de purismo (imperdonable entonces) a todo su grupo», lo cual le hace exigir una poesía humana, respondiendo tardíamente a Ortega, y considerar la deshumanización un concepto inadmisible (Guillén, 1969a: 408). Pese a que Guillén reitera que en la poesía de su generación no se apreciaban ni deshumanización ni asepsia, lo cierto es que una y otra cosa, sentencia González, dominaban el clima estético de la época. Para probarlo, recuerda cómo el influjo de Valéry es reconocido y repudiado, también a posteriori, por Dámaso Alonso (1948: 176-178) 
en su artículo fundacional. $\mathrm{O}$ acude al Cernuda asimismo sensible a la tentación de la pureza, como demuestra su predisposición a heredar de Reverdy, como él mismo reconoce (Cernuda, 1958: 627), las cualidades de desnudez, pureza y reticencia. A pesar de todo, al entender de Ángel González (1976: 214), las «verdaderas tendencias» de Cernuda están mejor expresadas cuando aspira a decirlo todo en el poema, frente a la limitación impuesta poco antes por lo que se había llamado poesía pura (Cernuda, 1958: 640).

Bien es verdad que no todos los poetas del Veintisiete, aclara Ángel González, participaron por igual de la deshumanización diagnosticada por Ortega, aunque la mayoría de los artistas del momento estuvo de algún modo implicada en ella. Por lo demás, la pureza y la deshumanización fueron, a su juicio, una ambición o ideal relativos, que nunca pudieron llegar a hacerse realidad. Más aún: en contra de lo previsto por Ortega, «ese arte minoritario se convirtió, por la simple acción del tiempo, en un arte más bien popular y "contaminado”" (González, 1976: 214). Naturalmente, quien así habla no solo es el crítico o el historiador literario que ha podido comprobar cómo las cosas fueron a la postre "por caminos en 1925 inesperados», sino el poeta que comenzó a escribir en una coyuntura histórica y estética, la de la posguerra, ya necesariamente rehumanizada. No por ello Ángel González deja de insistir, apoyándose en el estudio de Cano Ballesta (1972), en que casi todos los poetas del Veintisiete cedieron a la "gran tentación» de la pureza y la deshumanización, como indica la selección rigurosa de la tradición literaria que operaron estos «nietos de Góngora». Tentación de pureza que, a la vez, estuvo en el origen de su aproximación a Juan Ramón Jiménez, cuya poesía desnuda e intelectualizada «suponía el más próximo punto de apoyo para ascender directamente a la atmósfera aséptica e incontaminada a la que aspiraban» (González, 1976: 215). Todo ello hasta que, en el transcurso de los años treinta, cuando los jóvenes ya han mostrado una acusada personalidad (y la pureza, habría que añadir a este razonamiento de González, deja paso al surrealismo y al compromiso), «la luna de miel entre maestro y discípulos puede darse por concluida» (ibíd.).

Lo que interesa a Ángel González, como crítico y antólogo del Veintisiete, son los rasgos que agrupan, y no los que diferencian, a los poetas que selecciona, la uniformidad dentro de su diversidad, sobre la que llama convenientemente la atención. Trata, por lo tanto, de atender a la estética que los convirtió en grupo. No sin matizar que el tiempo, las guerras y otros desastres colectivos y personales alteraron por completo «el riguroso árbol genealógico 
inicial de los poetas del 27» (González, 1976: 216). Tanto es así, en efecto, que ya en esos años treinta, o más en concreto después del homenaje gongorino, se ha roto entre ellos la unidad estética y no puede hablarse, en estricto, de un solo grupo o generación (Mainer, 1997: 342-343). Lo subraya el propio González: «El surrealismo, que nada significa para Guillén, resulta muy pronto fundamental para Vicente Aleixandre» (González, 1976: 216).Y otro tanto podría decirse, tomando todavía como punto de referencia la poesía pura guilleniana, del compromiso revolucionario del que participan Prados y Alberti. Claro que, durante el periodo en que se configuraron como grupo, puntualiza Ángel González, los del Veintisiete descartaron a aquellos poetas que, como indica Diego en el prólogo citado, lastraron sus versos con «preocupaciones e intereses al fin y al cabo ajenos a la perfecta autonomía de la voluntad poética» (en Soria Olmedo, 1991: 668). En esta categoría entraban, entre los contemporáneos, Unamuno y Machado, cuyas obras resultaban «decididamente impuras por sus "contaminaciones" éticas, sentimentales, religiosas, biográficas o políticas» (González, 1976: 216). A pesar de que Unamuno y Machado abren la antología de Diego, el interés de los jóvenes por ellos es escaso, «rayano en el desdén si se compara con el fervor juanramoniano característico del momento» (ibíd.: 217). No se puede decir que la crítica literaria de Ángel González caiga en el mero descriptivismo. Porque siempre se encuentra determinada por la toma de partido estético; y por la experiencia histórica que le impulsó a adoptarla: Machado y Unamuno habían desplazado a Juan Ramón como modelos poéticos en la posguerra, de acuerdo con un proceso que culmina — con el inevitable revuelo, por la exclusión juanramoniana y la entronización machadiana- en Veinte años de poesía española (1960), de José María Castellet.

Por encima de su admiración a Juan Ramón Jiménez, Ángel González pone de relieve que su desmesurada figura dejó en la sombra durante los años veinte a los otros dos grandes poetas de principios de siglo. Machado, puntualiza en nota a pie de página, coincidió en el fondo con Ortega a la hora de caracterizar el arte de entreguerras: el juego, la alegría, la deportividad, el hermetismo; pero se le notaba que no era partidario, de forma que en él adquiría connotaciones negativas lo que en Ortega se percibía con resonancias entusiastas. Más adelante, en su discurso de ingreso en la Real Academia,Ángel González pondrá frente a frente, con detenimiento, el ideario estético de Ortega y el de Machado (González, 1997: 117-128). Pero ya en 1976, la fecha en que publica sus estudios 
críticos sobre Juan Ramón y sobre elVeintisiete, el Ángel González que nunca pierde de vista la Historia de la literatura, ni por consiguiente la Historia, apunta que esta acabaría dándole la razón a Machado y no a Ortega y los poetas puros: «Con el tiempo -iquién lo diría!- los poetas del 27 acabarían estando más de acuerdo con las agresivas puntualizaciones de Machado que con las estimulantes notas de Ortega» (González, 1976: 218). Para empezar, porque la influencia del surrealismo sobre el Veintisiete trae la «descomposición de los ideales de pureza que caracterizaron - parcial, aunque decisivamente- al grupo».

Tras acudir al testimonio crítico de Guillén (1969b: 514-515), para quien el surrealismo habría supuesto solo una invitación a la libertad imaginativa, y al más biográfico-literario de Cernuda (1958: 634), para quien fue una corriente espiritual ante la cual no pudo ni quiso permanecer indiferente, González precisa, de acuerdo con la «abundante bibliografia dedicada recientemente al tema», entre la que cita a Bodini (1971) y a Corbalán (1974), que el surrealismo no significó en nuestra literatura lo mismo que en la francesa. No obstante, también acude al Cernuda crítico, que clasifica a los poetas delVeintisiete en dos subgrupos en función de la influencia surrealista: Salinas y Guillén, por un lado, que quedan al margen de ella, y Lorca, Prados, Aleixandre, Alberti y Altolaguirre por otro, que sí que la acusan (Cernuda, 1957: 192), como ocurre con otros nombres (Larrea, Hinojosa, el propio Cernuda, y el más discutible de Diego) que González añade a la relación cernudiana. No fue solo la influencia del surrealismo, como bien señala Ángel González, lo que contribuyó a quebrantar los ideales de pureza, porque a la vez contribuyeron a ello la agitación y los cambios que conoció la sociedad española con motivo de la liquidación de la monarquía y el advenimiento de la república. Entre los del grupo, Alberti y Prados son los primeros en aproximar conceptos hasta entonces distantes como la poesía y la política. Por eso, en estas circunstancias, sostiene González corrigiendo a Guillén, «el surrealismo llegó a ser algo más que un estímulo para la libertad de la imaginación: se convirtió en un excelente medio para expresar las inquietudes sociales que la poesía pretendía incorporar» (González, 1976: 220). Si la poesía impura que reivindica Neruda en Caballo verde para la poesía (1935) acoge las «creencias políticas», poco después, con la guerra civil, se generaliza y radicaliza la politización de los poetas; a la vez, como bien indica Ángel González, la guerra supondrá la dispersión del grupo, que deja de existir como tal. Planteamiento acertado, frente a quienes utilizan el Veintisiete como etiqueta destemporalizada, 
incluyendo en ella la obra de estos poetas posterior a la contienda, en favor de la pedagogía; aunque, paradójicamente, fuera ya en la posguerra cuando comenzó la construcción historiográfica de este marbete, tal y como lo empleamos hoy (Anderson, 2005: 122-131).

\section{TODAS LAS MANSIONES DE LA POESÍA}

Más allá de las diferencias que Ángel González pueda tener con las poéticas del grupo, sobre todo con su estética inicial de la poesía pura y en cierto modo deshumanizada, acaba otorgando al Veintisiete «el lugar de máximo privilegio en el panorama de la poesía española del siglo XX» (González, 1976: 221). La lírica española no volvió a alcanzar, continúa diciendo, cotas tan altas de intensidad y originalidad. De todas formas, no atribuye al azar esta posición privilegiada. La vanguardia, con su incitación a la libertad y la aventura, sirvió a estos poetas para ensanchar las posibilidades de la poesía lírica. Por otro lado, pudieron conectar con «una tradición sin lastres, toda impulso y estímulo, abierta a direcciones hasta entonces inéditas» (ibíd.: 222). De modo que los poetas del Veintisiete no desperdiciaron la oportunidad, y en un plazo de poco más de diez años (recordemos: el decenio 1925-1935) «lo intentaron casi todo, y lograron la mayor parte de las metas que se propusieron». Volvemos así a la idea según la cual ocuparon todas las mansiones de la poesía disponibles, reduciendo las posibilidades de las promociones que vinieron después, como señala Eliot (1945: 63) que hacen los grandes poetas. Ángel González no cita a Eliot, pero coincide con él cuando escribe que la generación que vino después pagó las consecuencias: los poetas del 36 se encontraron con que los caminos anchos e infinitos por los que habían circulado sus hermanos mayores ("desde la exploración vanguardista hasta la rebusca de viejos modelos en el Siglo de Oro») resultaban ya imposibles por excesivamente transitados. Por eso acabaron haciéndose un sitio en el único lugar que les había quedado libre, «junto a los rescoldos de Machado y Unamuno», dos poetas a los que, a decir de Ángel González (1976: 223), era fácil repetir y muy dificil continuar. No pierde de vista, de nuevo, el papel fundamental de la Historia, y así considera justo reconocer que la guerra civil y el clima opresivo de la posguerra no resultaron estimulantes ni para los poetas del 36 ni para ninguna de las promociones que les sucedieron. Pues el descenso cultural y el retroceso social que se produjeron en España a partir de 1936 tenían que reflejarse en 
la poesía: «En resumen: si el siglo XX español —al menos hasta la fecha - estaba destinado a producir una gran promoción lírica, esa promoción habría de darse donde efectivamente surgió: en la generación a la que pertenecen los poetas del 27» (ibíd.).

Bastantes años después, Ángel González se ocupará con mayor pormenor, como ya se ha dicho, de la presencia del Veintisiete en las promociones posteriores. Llama la atención, en primer lugar, sobre las muchas y tan contradictorias opciones como ofrece el magisterio de estos poetas; y sobre el hecho de que su estética cambió tanto con los años, pasó por estadios tan diversos, que resulta imposible tomar como modelo un aspecto del Veintisiete sin rechazar otros:

Entre la tradición y la vanguardia, entre lo culto y lo popular, entre la lucidez y la irracionalidad, entre la pureza y la revolución: esos son algunos de los extremos entre los que se mueve la obra lírica del 27. Los poetas que vinieron después, pertenecientes a promociones con planteamientos estéticos muy definidos — por no calificarlos de dogmáticos- tuvieron que verse obligados a elegir y a descartar modelos (González, 1993: 238).

Una vez sentada esta premisa, vuelve sobre la idea de que para la generación del 36 el ejemplo del Veintisiete debió de presentar serios problemas, a causa de su excesiva proximidad: «¿Qué podían hacer entonces, cuando nada quedaba ya por inventar, los poetas jóvenes, los poetas destinados a configurar otra generación?» (ibíd.: 239). Pudieron haber partido, a decir de Ángel González, del territorio amplio y libre que habían abierto el surrealismo y el compromiso, pero la generación del 36 era, como señaló Cernuda, conservadora, y esto le impidió asumir lo que había de impuro y de ideológico en aquella posibilidad. Para definir su perfil propio, no tuvieron más remedio, vuelve a plantear aquí, que apoyarse en Unamuno y Machado, «hasta entonces marginados - muy respetuosamente, pero marginados- por los autores del 27» (ibíd.: 240). Con el matiz de que lo que trataron de actualizar de estos dos poetas fue solo aquello que convenía a su mentalidad conservadora: los temas de Dios y la familia, y la contemplación idealizadora y trascendente del paisaje castellano, convertida desde muy pronto en vehículo de un fervoroso sentimiento nacionalista. Todo ello, sentencia Ángel González, opuesto en su conjunto al «espíritu del 27». Por otro lado, la vuelta del 36 a las formas clásicas, y su insistencia en el soneto, propiciadas por la inminencia del cuarto centenario 
de la muerte de Garcilaso, le parecen una «desviación hacia atrás» con respecto al último rumbo marcado por el Veintisiete, que había llevado poco antes al auge del versolibrismo y de la influencia surrealista. La independencia de criterio que fundamenta la crítica literaria de Ángel González solo puede comprenderse a partir del poeta que tiene muy clara la tradición en la que ha tratado de situarse desde el comienzo de su trayectoria. $\mathrm{O}$ al menos, la que resulta más afín a su poética. Matiza, quizás por eso, que dentro del 36 hubo quienes, como Serrano Plaja, Gil-Albert o Miguel Hernández, compartieron en la vida y en el arte, negando la tendencia conservadora de la mayoría, «las ideas nuevas y radicales puestas en circulación por los poetas del 27» (ibíd.: 241). No en balde, añade a continuación que fueron algunos «representantes rezagados» de la promoción del 36, como Celaya y Otero, quienes en circunstancias poco propicias reanudaron en la posguerra la línea social y comprometida iniciada antes de 1936. El crítico literario rompe una lanza por la tradición (la poesía comprometida del Veintisiete, la poesía social de Celaya y Otero) a la que se sumó como poeta desde los años cincuenta:

La poesía social de la posguerra, juzgada con poca simpatía actualmente, no fue solo una servidumbre de la dictadura o una inevitable respuesta a ella; también debe ser vista como la recuperación de una tendencia violentamente interrumpida. Por ese extremo del 27, por el lado del compromiso y del realismo, prolongaron algunos poetas del 36 la labor de la generación anterior (ibíd.).

La siguiente parada que realiza Ángel González en este recorrido es la de los poetas de los años cincuenta, que a su modo de ver, y habla lógicamente "con mejor conocimiento de causa», no sintieron con respecto al Veintisiete esa excesiva proximidad que pudo agobiar a la generación del 36. La razón está en la distancia que los separaba de ellos, y que les parecía incluso remota lejanía, magnificada por los efectos de la guerra civil. En esas condiciones, aclara, conocieron la obra delVeintisiete en su imagen más pura: la que ofrece la antología de Diego; y a partir de aquí desarrolla argumentos que ya conocemos: ese primer contacto bastó para deslumbrarlos, con lo cual se esforzaron por conocer a esos poetas de modo más completo, tarea que coincidió con su etapa formativa. Para sentenciar: «Tal vez por eso todos reconocen el magisterio elemental del 27: en esa generación aprendieron a leer y a escribir» (González, 1993: 242). Por lo que se refiere a los aspectos concretos 
del Veintisiete que interesaron al 50, el crítico literario, ya transustanciado en el poeta, o al revés, señala la «rotación de preferencias» que se produjo: Salinas, Guillén, Lorca, Alberti o Aleixandre reclamaron sucesivamente la atención del grupo, hasta que esta se centró, ya en los años sesenta, en Luis Cernuda. Precisamente en este punto, en el del ejemplo de Luis Cernuda para el 50, Ángel González alude al Gil de Biedma para quien se impuso la necesidad de reaccionar conscientemente contra la poesía en cuyo magisterio se habían educado él y sus compañeros de grupo, la poesía del Veintisiete (Gil de Biedma, 1962: 67). Pero, como advierte con sagacidad González, y de nuevo con independencia de criterio, con fidelidad absoluta al núcleo duro de su poética, Biedma habla de lo oportuno de esa reacción en 1962, una fecha equidistante de la publicación de sus libros Compañeros de viaje y Moralidades, "cuando estaba entregado sin reservas, o con pocas reservas, a la escritura comprometida» (González, 1993: 242). De aquí que descubra en su planteamiento un error de apreciación: esa reacción «en contra» en realidad se dirigía por entonces a la poesía pura, pero en el Veintisiete podían encontrarse a la altura de los años sesenta, además de pureza, "otras muchas cosas aprovechables para quienes quisieran meter la poesía en el carro de la historia» (ibíd.). Todavía parafraseando a Biedma, Ángel González concluye que lo que el Veintisiete dejó en la promoción del 50 «fue esa clase de buena educación que, aunque la vida nos depare nuevas amistades y nos lleve a frecuentar otros ambientes, no se pierde nunca» (ibíd.: 243).

Por el contrario, los novísimos volvieron sus ojos hacia «los incontaminados destellos de pureza lírica» que les ofrecía elVeintisiete. Ángel González los presenta cohesionados por el intento radical de romper con el pasado inmediato, con los tiempos penosos de la guerra y la dictadura, movidos por un "precipitado afán de perder la memoria histórica» y de repudiar «toda la literatura que supusiera una respuesta a la historia, o su reflejo» (González, 1993: 243). Ignoraron así lo que el Veintisiete había significado en el periodo anterior, para los poetas del 50, y reclamaron «con exclusividad» la posesión de su valioso legado (ibíd.: 244). No debe pasarse por alto que este razonamiento de González, del crítico literario y del poeta en que nunca deja de sustentarse, se halla determinado por la atención que presta a lo largo de su obra a «la preocupación por la entidad y las situaciones de la poesía», al género poético en abstracto, atendiendo a qué es y debe ser la poesía, y a los debates de actualidad poética, defendiendo sus posiciones (García Montero, 2006: 34). De la crítica a los novísimos da cuenta, como es bien sabido, la 
«Oda a los nuevos bardos», de Muestra, corregida y aumentada, de algunos procedimientos narrativos (1977), aunque la censura de los «poetas celestiales», por decirlo con la expresión de José Agustín Goytisolo, ya lo había llevado mucho antes de esta diatriba contra la estética novísima (Payeras Grau, 2009: 131-133) a emitir «juicios muy similares sobre los líricos de entonación garcilasista» (Prieto de Paula, 2002: 281). Nada tan claro como que la defensa de sus posiciones frente a las de los novísimos se encuentra otra vez determinada por la atención que Ángel González siempre presta a la Historia. No va descaminado cuando, en otro momento anterior, considera con lucidez la poesía "pretendidamente» novísima como la última manifestación de la cultura del franquismo: «Si la poesía novísima rompe expresamente con algo no es con la cultura franquista — que deja cuidadosamente a un lado-, sino con la otra cultura, con la cultura que intentó oponerse al franquismo» (González, 1980:387). Desde aquí nos podemos explicar que se niegue a otorgar a los novísimos la exclusividad del legado del Veintisiete, con olvido de lo que este, en su vertiente «realista» y comprometida, había supuesto para la promoción anterior. Tampoco los novísimos, advierte, podían llevar a cabo el reenlace con el Veintisiete sin reservas y negaciones, pues sus propios postulados imponían el «repudio de toda la carga histórica y moral» asumida por aquel (González, 1993: 244).

\section{DESDE EL CENTRO DE LA HISTORIA}

Hay otros muchos aspectos dignos de mención en los dos trabajos críticos que Ángel González dedica al Veintisiete. No obstante, quizás tengan más interés para el estudioso de ese conjunto de poetas que para el espectador atento a cómo González los lee y se sitúa ante ellos, a cómo maneja su legado, tanto poética como críticamente, si es que, como he venido planteando hasta aquí, cabe separar ambas facetas. Porque nos encontramos, por lo general, ante un poeta en función de crítico. Esos otros aspectos hablan, de todas formas, de un crítico lúcido y personal, con voz propia y clara, muchas veces desmitificadora, entre la bibliografia dedicada al Veintisiete. Por ejemplo, la consideración de estos poetas como un grupo coherente y cerrado dentro de un marco más amplio, lo cual le induce a desvanecer la «ilusión generacional» y a denunciar la «sinécdoque frecuentísima» que ha llevado a la crítica a muchas confusiones, al tomar la parte por el todo (González, 1976: 197); la atención a las afinidades electivas, de carácter estético, además de 
la amistad, que cohesionaron alVeintisiete, desde el homenaje gongorino a la antología de Diego (ibíd.: 200); el comentario detenido y perspicaz de los seis títulos que se han usado, con diversa fortuna, para definir al grupo: generación del 27 o «nietos de Góngora», generación de la amistad, generación de los poetas-profesores, generación Guillén-Lorca, generación de 1925 y generación de la dictadura (ibíd.: 201-206), denominación esta última que no le parece tan inoportuna; y aquí sí que aflora más claramente el poeta junto al crítico, puesto que, basándose en el Jorge Guillén (1969a: 409) que protesta por el calificativo de "vanguardistas» aplicado a su grupo, dado que esta metáfora militar no convenía a su juicio a quienes no luchaban con nadie en ningún frente, y en el Dámaso Alonso (1948: 174) que afirma cómo entre ellos no hubo sentido conjunto de protesta política, ni aun de preocupación política, Ángel González espeta, no muy lejos en realidad de lo que habían hecho Unamuno o Giménez Caballero ante tanto furor neogongorino, que «escritores así son los que las dictaduras necesitan y fomentan» (González, 1976: 207).

Igualmente, merecen destacarse, en este primer trabajo, el análisis que Ángel González realiza de las relaciones armónicas entre continuidad y ruptura, tradición y originalidad, en la poesía del Veintisiete (González, 1976: 207); la reivindicación de las aportaciones del ultraísmo, que a su entender no se reducen a liquidar los vestigios de la retórica modernista, si bien, dada la militancia vanguardista de los ultraístas, surgen de «una posición opuesta a la que adoptaron los poetas del 27» (ibíd.: 208-209); o bien el dibujo de un mapa de la lírica española en torno a los años veinte más rico, en el que no cabe olvidar a poetas inmediatamente anteriores como Moreno Villa, Basterra, Bacarisse, Domenchina, Espina o Chabás (ibíd.: 209-211), algunos de los cuales son mencionados explícitamente por Diego en el prólogo a su selección por no cumplir satisfactoriamente, como indica González, las exigencias estéticas del grupo, basadas en el divorcio radical de poesía y literatura. Desde luego, vuelve a dar en el blanco cuando escribe, adelantándose a los estudios actuales sobre cómo este grupo se hizo con el centro del canon, que "con suaves, casi corteses e inteligentes codazos, los poetas del 27 lograron abrir un capítulo para ellos solos en la abigarrada nómina lírica de los años veinte» (ibíd.: 225). Este es el hecho fundamental del que parte para su antología del grupo, en la que incluye trece nombres (los diez usuales, junto a Hinojosa,Villalón y Larrea) para respetar la «voluntad de ser» de los poetas del Veintisiete y no correr el riesgo de desvirtuar «uno 
de los capítulos más admirables — con sus posibles defectos, y tal vez, en parte, a causa de algunos de ellos- de nuestra literatura moderna» (ibíd.: 227).

El segundo trabajo crítico sobre el Veintisiete, ahora considerado como "generación», busca someter a «la prueba de la duda o incluso de la negación» algunas de las ideas más reiteradas a propósito de ella. Así, Ángel González denuncia la «imagen convencional» del Veintisiete ofrecida por manuales y panoramas críticos, que a su juicio ha desembocado en "una visión deformadora y empequeñecedora del periodo más rico y creativo de nuestra historia moderna, en el que culmina el largo proyecto de universalidad puesto en marcha en el siglo XVIII» (González, 1993: 229). Punto de partida que lo lleva a señalar la necesidad de conectar la poesía del Veintisiete - que no fue tan pura como suele decirse, ni exclusivamente lírica, y cuya grandeza «le cayó, en parte, del cielo o del infierno de la historia» (ibíd.: 230)— con la música, el teatro, el cine, el arte popular, la pintura o incluso la política de aquel periodo; y a discutir la "nómina de la generación», como ya antes había hecho. Todo ello entrando en diálogo crítico con estudios como los de Siebenmann (1973), González Muela y Rozas (1986), Cano Ballesta (1972) o Díez de Revenga (1987), sin dejar de acudir a documentos de primera mano como el ya citado artículo fundacional de Dámaso Alonso, que sirve a Ángel González para ilustrar la «operación autoafirmativa» llevada a cabo por el Veintisiete en su «versión minimalista» (ibíd.: 232-233), el «espíritu de clan»al que se refirió Guillermo de Torre (1962: 267), de cuyos planteamientos ya se hacía eco González en el trabajo de 1976. Incluso propone incardinar al Veintisiete en una "comunidad más amplia», abarcadora de todo el ámbito del idioma, considerarlo como resultado de "un impulso o tendencia supranacional», abogando por estudiar sus coincidencias y paralelismos con el grupo mexicano de los Contemporáneos (González, 1993: 235). No son en absoluto desdeñables, en fin, sus observaciones sobre el modernismo y la poesía del Veintisiete, y en concreto la sutil huella que descubre del Darío de «Estival», de $A z u l . .$. , con su clima erótico y amenazador, en el Aleixandre de La destrucción o el amor (ibíd.: 237-238 y 1989: 78).

Hablando de su experiencia como profesor universitario, Ángel González nos cuenta cómo este trabajo, que le resultó muy estimulante al principio, lo llevó a intentar un género para él nuevo, la crítica y el ensayo literario, a sabiendas de sus limitaciones como erudito: «Lo que he publicado en este terreno tiene más de aventura personal que de trabajo de erudición» (González, 1990: 
428). Pudiera ser; pero recorrer esa aventura personal, como he tratado de hacer a partir de sus estudios sobre el Veintisiete, depara sorpresas inesperadas. Sobre todo porque consuela leer, en este no menos áspero mundo de hoy en día, incluido el de los nuevos bardos, que «la literatura forma parte de la Historia, es Historia ella misma» (González, 1977: 303). O que la Historia de la poesía, la Historia de la literatura, «no es más que un fragmento de la Historia» (González, 1963: 450). Desde mi punto de vista, no hay duda de que esa convicción parte de su confesada atracción por el marxismo, que ya en los años cincuenta le parecía una visión muy inteligente del hombre y de la Historia: «No comparto la opinión de quienes predican el fin del pensamiento marxista, que en mi opinión tiene aún muchas posibilidades de desarrollo» (González, 1990: 435). Aquí, en su voluntad de escribir «desde el centro de la Historia», y no «desde la pretendida inmutabilidad de la naturaleza humana» (González, 1963: 452), radica el compromiso poético y crítico de Ángel González, el poeta que siempre ha tenido claro, con Luis Cernuda, que en la morada de la poesía hay muchas mansiones: «Lo que ocurre es que un poeta no puede ocuparlas todas, está obligado a elegir su propio espacio, por fuerza limitado, y desde él piensa, opina y escribe. Cuando un poeta habla de poesía, está justificando o defendiendo, aunque no lo sepa, su posición dentro de la gran "morada” en la que habita» (González, 2002: 478). Así Ángel González, crítico literario del Veintisiete. 


\section{BIBLIOGRAFÍA}

Abad, Francisco (1990). «Crítica literaria y lengua poética de Ángel González», Anthropos, 109, pp. 55-57.

Alonso, Dámaso (1948). «Una generación poética (1920-1936)», Poetas españoles contemporáneos, Madrid, Gredos, 1952, pp. 167-192.

Anderson, Andrew A. (2005). El Veintisiete en tela de juicio, Madrid, Gredos.

Bodini,Vittorio (1971). Los poetas surrealistas españoles, Barcelona, Tusquets.

Bousoño, Carlos (1977). La poesía de Vicente Aleixandre, Madrid, Gredos, 4. ${ }^{a}$ ed.

Cano Ballesta, Juan (1972). La poesía española entre pureza y revolución (1930-1936), Madrid, Gredos.

Cernuda, Luis (1957). «Generación de 1925», en Cernuda (2002), pp. 181-239.

— (1958). «Historial de un libro», en Cernuda (2002), pp. 625-661.

— (1959). «Experimento en Rubén Darío», en Cernuda (2002), pp. 711-721.

- (2002). Obra completa. Prosa I, eds. Derek Harris y

Luis Maristany, Madrid, Siruela, 2. ${ }^{\text {a }}$ ed.

Corbalán, Pablo, ed. (1974). Poesía surrealista en España, Madrid, Ediciones del Centro.

Díaz de Castro, Francisco (2006). «Los otoños de Ángel González», en Guerrero, Peregrina y Salvador (2006), pp. 93-107.

Díez de Revenga, Francisco J. (1987). Panorama crítico de la generación del 27, Madrid, Castalia.

- (2003). La tradición áurea. Sobre la recepción del Siglo de Oro en poetas contemporáneos, Madrid, Biblioteca Nueva.

Eliot, T. S. (1945). «¿Qué es un clásico?», en Sobre la poesía y los poetas, Buenos Aires, Sur, 1959, pp. 50-69.

García, Miguel Ángel (2001a). El Veintisiete en vanguardia. Hacia una lectura histórica de las poéticas moderna y contemporánea,Valencia, Pre-Textos.

- (2001b). Vicente Aleixandre, la poesía y la historia, Granada, Comares (De guante blanco).

- (2010). «Tres siglos después de Góngora. Hacia la pura existencia estética», en Rumor renacentista. El Veintisiete, eds. Antonio Jiménez Millán y Andrés Soria Olmedo, Málaga, Centro Cultural Generación del 27, pp. 131-202. 
- (2011). «¿Hacia una reconfiguración radical del canon? El Veintisiete y la dialéctica de la vanguardia en España», Anales de la Literatura Española Contemporánea, 36, 1, pp. 55-80.

- (2012). La literatura y sus demonios. Leer la poesía social, Madrid, Castalia.

- (2013a). «Autobiografia, conocimiento y experiencia en Francisco Brines (La sombra confortable de Luis Cernuda)", en Huésped del tiempo esquivo. Francisco Brines y su mundo poético, ed. Sergio Arlandis, Sevilla, Renacimiento, pp. 384-427.

- (2013b). «Luis Cernuda desde América. Correspondencias con Gil de Biedma», en Queridos todos. El intercambio epistolar entre escritores hispanoamericanos y españoles del siglo XX, eds. Ana Gallego Cuiñas y Erika Martínez, Bruselas, Peter Lang, pp. 115-124.

García de la Concha,Víctor (1991). «Más allá de la generación del 27: la década prodigiosa (1920-1930)», Ínsula, 529, pp. 3-4.

García Montero, Luis (2002). «Conversación con Ángel González», Litoral, 233, pp. 16-25.

- (2006). «Historia y experiencia en la poesía de Ángel González», en Guerrero, Peregrina y Salvador (2006), pp. 27-40.

Gil de Biedma, Jaime (1962). «El ejemplo de Luis Cernuda», en El pie de la letra. Ensayos completos, Barcelona, Crítica, 1994, pp. 63-68.

- (1985). «Ángel», en Guía para un encuentro con Ángel González, Oviedo, Luna de Abajo / Tribuna Ciudadana, 1997, 3. ${ }^{a}$ ed. aum., pp. 33-34.

GonzÁlez, Ángel (1963). «Poesía y compromiso», en González (2005), pp. 450-452.

— (1976). «El grupo poético de 1927», en González (2005), pp. 195-227.

— (1977). «La obra poética de Gabriel Celaya», en González (2005), pp. 287-311.

- (1980). «Poesía española contemporánea», en González (2005), pp. 379-387.

— (1989). «Azul... y la poesía española del siglo XX», en González (2005), pp. 60-79.

- (1990). «Autopercepción intelectual de un proceso

histórico», en González (2005), pp. 417-449.

- (1991). «El exilio en España y desde España», en González (2005), pp. 249-265.

— (1993). «La poesía de la generación del 27», en González (2005), pp. 228-246.

- (1994). «Intertextualidad e interdiscursividad en la poesía de

Gabriel Celaya», en González (2005), pp. 312-332.

— (1997). «Las otras soledades de Antonio Machado», en González (2005), pp. 101-134.

— (2002). «Sobre la poesía: un alegato», en González (2005), pp. 477-484.

— (2004). «La poesía desnuda», en González (2005), pp. 176-180.

- (2005). La poesía y sus circunstancias, ed. José Luis García Martín, Barcelona, Seix Barral. 
GonzÁlez Muela, Joaquín y Rozas, Juan Manuel, eds. (1986). La generación poética de 1927. Estudio, bibliografía y antología, Madrid, Istmo.

Goytisolo, José Agustín (1998). «[Ángel González tuvo un papel importantísimo como enlace entre los poetas de Barcelona y Madrid]", en Ángel González en la generación del 50. Diálogo con los poetas de la experiencia, Oviedo, Tribuna Ciudadana, p. 20.

Guerrero, José, Peregrina, Elena y Salvador, Álvaro, eds. (2006). Ángel González, un clásico de nuestro tiempo, Almería, Universidad de Almería.

GuilLÉn, Jorge (1969a). «Lenguaje de poema: una generación», en Guillén (1999), pp. 403-412.

— (1969b). «El estímulo superrealista», en Guillén (1999), pp. 511-514.

- (1999). Obra en prosa, ed. Francisco J. Díaz de Castro, Barcelona, Tusquets.

Hierro, José (1997). «Sobre Ángel González», en Guía para un encuentro con Ángel González, Oviedo, Luna de Abajo / Tribuna Ciudadana, 3. a ed. aum., pp. 58-59.

IraveDrA, Araceli (2008). «Ángel González y el pleito de la poesía», Cuadernos Hispanoamericanos. Los Complementarios, 17, pp. 68-83.

Jiménez Millán, Antonio (2002). «Luis Cernuda en la poesía española contemporánea», en Luis Cernuda 1902-1963, ed. James Valender, Madrid, Consejería de Cultura de la Junta de Andalucía / Centro Andaluz de las Letras, pp. 109-134.

- (2006). «Ángel González: crónicas y notas de un viajero», en Guerrero, Peregrina y Salvador (2006), pp. 87-92.

Mainer, José-Carlos (1997). «Alrededor de 1927: historia y cultura en torno a un canon", en Historia, literatura, sociedad (y una coda española), Madrid, Biblioteca Nueva, 2000, pp. 333-353.

Morelli, Gabriele (1997). Historia y recepción de la Antología de Gerardo Diego,Valencia, Pre-Textos.

— (2007). «La Antología en la generación del 27», Ínsula, 721-722, pp. 7-9.

Payeras Grau, María (2009). El sueño de la realidad. Poesía y poética de Ángel González, Santa Cruz de Tenerife, La Página.

Pozuelo Yvancos, José María (2003). «La crítica literaria de Luis Cernuda», en Poéticas de poetas. Teoría, crítica y poesía, Madrid, Biblioteca Nueva, 2009, pp. 179-194.

Prieto de Paula, Ángel L. (2002). «Ángel González, la fuerza del desaliento", Litoral, 233, pp. 278-283.

Rivera, Susana (2006). «Intertextualidad y collage», en Guerrero, Peregrina y Salvador (2006), pp. 41-57.

Rovira, Pere (2006). «Los prosemas de Ángel González», en Guerrero, Peregrina y Salvador (2006), pp. 59-64. 
Siebenmann, Gustav (1973). Los estilos poéticos en España desde 1900, Madrid, Gredos.

Siles, Jaime (2002). «Cernuda en el espejo de las generaciones», Revista de Occidente, 254-255, pp. 77-94.

Soria Olmedo, Andrés (1988). Vanguardismo y crítica literaria en España, Madrid, Istmo.

— ed. (1991). Antología de Gerardo Diego. Poesía española contemporánea, Madrid, Taurus.

- ed. (2007). Las vanguardias y la generación del 27, Madrid,Visor.

— (2010). «Generaciones y semblanzas», en Rumor renacentista. El

Veintisiete, eds. Antonio Jiménez Millán y Andrés Soria Olmedo, Málaga, Centro Cultural Generación del 27, pp. 17-59.

Talens, Jenaro (1990). «Lecturas de Luis Cernuda desde la generación de 1950», en Actas del Primer Congreso Internacional sobre Luis Cernuda (19021963), ed. Jacobo Cortines, Sevilla, Universidad de Sevilla, pp. 51-60.

Teruel, José, ed. (2007). Gerardo Diego, Poesía española (Antologías), Madrid, Cátedra.

Torre, Guillermo de (1962). «[Una generación literaria más amplia]», en Historia y crítica de la literatura española. Época contemporánea 1914-1939, ed.

Víctor García de la Concha, Barcelona, Crítica, 1984, pp. 266-268. 